\title{
Transient Monocytosis Subjugates Low Platelet Count in Adult Dengue Patients
}

\author{
Jih-Jin Tsai ${ }^{a-d}$ Jung-San Chang ${ }^{\text {e, }}$ Ko Chang $^{a-d, g}$ Po-Chih Chen ${ }^{a, h, i}$ \\ Li-Teh Liuc, j Tzu-Chuan Hok Sia Seng Tank ${ }^{k}$ Yu-Wen Chien' \\ Yu-Chih Lom ${ }^{m}$ Guey Chuen Perngk, n
}

\begin{abstract}
${ }^{a}$ Tropical Medicine Center, ${ }^{b}$ Division of Infectious Diseases, Department of Internal Medicine, ${ }^{\mathrm{C}}$ Center for Dengue Fever Control and Research, d School of Medicine, and ${ }^{\mathrm{e}}$ Department of Renal Care, College of Medicine, Kaohsiung Medical University, ${ }^{f}$ Division of Gastroenterology, Department of Internal Medicine, Kaohsiung Medical University Hospital, ${ }^{9}$ Department of Internal Medicine, Kaohsiung Municipal Siaogang Hospital, h Department of Laboratory Medicine, Kaohsiung Medical University Hospital, and 'Department of Medical Laboratory Science and Biotechnology, College of Health Sciences, Kaohsiung Medical University, Kaohsiung City, and ${ }^{j}$ Department of Medical Laboratory Science and Biotechnology, College of Medicine and Life Science, Chung-Hwa University of Medical Technology, Departments of ${ }^{k}$ Microbiology and Immunology and 'Public Health, College of Medicine, National Cheng Kung University, ${ }^{\mathrm{m}}$ Department of Biotechnology and Bioindustry Sciences, College of Bioscience and Biotechnology, National Cheng Kung University, and ${ }^{n}$ Center of Infectious Disease and Signaling Research, National Cheng Kung University, Tainan, Taiwan, ROC
\end{abstract}

\begin{abstract}
What Is It about?
Although adult dengue has escalated in recent years globally, hematological parameters have seldomly been systematically investigated and characterized. Retrospective laboratory data of confirmed adult dengue patients as well as specimens of a recent dengue outbreak were examined. Sudden downward platelet counts corresponding to a transient surge of monocytes on day 4 onward were seen. In addition, an inverse correlation between absolute monocyte and platelet counts was observed on day 5 in severe patients. Fluorescence-activated cell sorting (FACS) analysis of peripheral blood mononuclear cells obtained from recent acute dengue patients and experimental investigations revealed that phagocytic effects of innate immune cells contribute to thrombocytopenia in dengue patients.
\end{abstract}

\section{Keywords}

Innate immunity · Flaviviruses · Dengue - Dengue fever - Dengue hemorrhagic fever . Thrombocytopenia
Abstract
Background: Dengue is one of the most important vector-borne human viral diseases glob- ally. The kinetic changes of hematological parameters of dengue in adult Taiwanese patients have seldomly been systematically investigated and characterized. Methodology/Principal
Guey Chuen Perng, PhD
Department of Microbiology and Immunology
College of Medicine, National Cheng Kung University
Tainan 70101, Taiwan (ROC)
E-Mail gperng@mail.ncku.edu.tw
Co-corresponding author:
Yu-Chih Lo, PhD
Department of Biotechnology and Bioindustry Sciences
College of Bioscience and Biotechnology
National Cheng Kung University
Tainan 70101, Taiwan (ROC)
E-Mail gracelo@mail.ncku.edu.tw 
Findings: Serial laboratory data of 1,015 adult patients who were diagnosed with dengue virus serotype 2 (DENV2) and 3 (DENV3) infections in southern Taiwan were retrospectively examined. Prominent parameters were verified with specimens from a 2015 dengue outbreak. Higher absolute monocyte counts on day 5 in severe patients than mild fever subjects after the onset of fever was seen. The absolute number of monocytes was significantly greater in those with DENV2 than DENV3 infections in spite of subtle differences in laboratory tests. Platelet counts were lowest and activated partial thromboplastin time was highest on day 5 in patients with severe conditions. In addition, sudden downward platelet counts corresponding to a transient surge of monocytes on day 4 onward was observed. Fluorescence-activated cell sorting analysis of peripheral blood mononuclear cells obtained from acute dengue patients and experimental investigations revealed that phagocytic effects of innate immune cells contribute to thrombocytopenia in dengue patients. Conclusion: Innate phagocytic cells play an essential role in low platelet counts in adult patients with dengue virus infections.

(C) 2017 The Author(s)

Published by S. Karger AG, Basel

\section{Introduction}

Dengue fever (DF) is one of the most common mosquito-borne human viral diseases in the world. The disease has reemerged as a major public health problem in more than 100 countries in tropical and subtropical climate zones [1]. DF is a febrile illness caused by dengue virus (DENV) infection, which is estimated at approximately 390 million infections annually, resulting in 96 million symptomatic dengue cases and putting more than 500,000 at risk of dengue hemorrhagic fever (DHF) or dengue shock syndrome (DSS) [2]. Most patients with DENV infection manifest with a subclinical infection; however, symptomatic DENV infections can range from a febrile DF to severe and life-threatening DHF/DSS [3].

The pathogenesis of DHF/DSS remains to be further delineated in spite of several decades of intensive investigations. Many hypotheses have been implicated, including antibodymediated enhancement on viral entry and replication in Fc-bearing phagocytic cells [3], individual genetic background [4], viral strain differences [5], a cascade of cytokine storm resulting from viral infection in immune cells [6], and hematological disorders [7, 8].

Despite the fact that the target cells of DENV remain in debate, reports indicate that phagocytic cells and progenitor cells for platelets are likely candidates [9-11], and the latter may play a role in dissemination of the virus [12]. Interestingly, preexisting antibodies acting on bone marrow progenitor cells could facilitate entry, replication, and spread of DENV by a process known as antibody-dependent enhancement have been reported [13]. Infected phagocytic cells may activate other effector mechanisms to produce vasoactive cytokines that cause endothelial cell damage resulting in transient plasma leakage in DHF [6]. Alternatively, activated phagocytic cells can produce proinflammatory cytokines by the CLEC5A-mediated signaling to induce DHF [14]. However, the abnormal hematological events, such as low platelet counts and dysfunctional platelets, which reduce the adhering and healing capacity in the blood vessel bed in infected patients, should not be ruled out for DHF development.

Thrombopathy includes platelet dysfunction and low platelet counts, which are the salient clinical findings in dengue patients. Experimentally, there are many cells capable of supporting DENV infections, and yet its counterparts in vivo remain to be resolved. In general, immune cells with phagocytic capacity have been suggested to be infectable by DENV, especially cells with mannose-related receptors [15], DC-specific ICAM3-grabbing nonintegrin molecules [16], and CLEC5A [14] on the surface. However, recent evidence suggests that other immune cells, such as platelets and its precursor cells, megakaryocytes, are a favored target of DENV as well [17-22]. The latter may partially explain the dysfunction of platelets 
resulting in prolonged activated partial thromboplastin time (aPTT) during the early phase of dengue disease, and subsequent low platelet counts when the disease progresses to a critical stage [1].

Leukopenia is common in patients with DENV infection [23] and thrombocytopenia is one of the most salient hallmarks in dengue patients. However, the reports on laboratory data of DF/DHF patients are predominantly from children younger than 14 years of age in dengueendemic regions $[23,24]$. In contrast, only few studies have discussed the kinetic changes in whole blood cells, platelets, lymphocytes, monocytes, and aPTT status in DENV-infected adult patients.

To better understand the complicated relationship between hematological parameters and the pathogenesis of adult dengue, we retrospectively examined the sequential laboratory measurements of defined parameters in adult dengue patients in Taiwan. Prominent parameters in the retrospective findings were further verified with specimens collected from a 2015 dengue outbreak. We report here that low platelet counts, prolonged aPTT, and transient monocytosis were observed on day 5, that NS1+ cells were most likely in CD61+CD14+ populations on day 4 onward, and that platelets upon exposure to DENV enhanced the capacity of engulfment by monocytes, which altered the phenotypes toward macrophages or dendriticlike cells after the phagocytosis of the DENV-activated platelets. These results suggested that phagocytic immune cells play a critical role in restriction of viral dissemination and in thrombocytopenia as well as influence the development of DHF in adult Taiwanese patients with DENV infections.

\section{Methods}

\section{Patient Recruitment}

The dengue clinical samples and human peripheral blood from healthy volunteer donors addressed in this article were approved by the institutional review boards of Kaohsiung Medical University Hospital (KMUH) and National Cheng Kung University with approval protocol No. 960195 and protocol No. B-ER-104-178, respectively.

We conducted a retrospective analysis of laboratory data from adult patients diagnosed with DENV infection between January 1998 and December 2007 at KMUH and Hsiao Kang Municipal Hospital, both located in Kaohsiung City in southern Taiwan. DENV infection was confirmed by the Taiwan Center for Disease Control (CDC). One or more of the following criteria were used for diagnosis: a positive reverse transcriptase-polymerase chain reaction for DENV RNA; positive DENV isolation; titer of dengue-specific IgM antibody greater than or equal to 1:40 in acute phase serum as suggested by the guidelines of Taiwan CDC, which is based upon the WHO statement; and a 4-fold increase in IgG antibody titer in convalescentphase serum by enzyme-linked immunosorbent assay (ELISA) [25]. DENV serotypes were detected by real-time reverse transcriptase-polymerase chain reaction using primers targeting the region of the capsid (C) gene after screening for all flaviviruses using a primer set targeted to the nonstructural protein 5 coding region. Then, 4 sets of serotype-specific primers targeting the $\mathrm{C}$ gene were used to differentiate the DENV serotypes of the positive samples [26]. Primary and secondary DENV infections in acute-phase and convalescentphase serum samples were detected and differentiated using envelope/membrane-specific capture IgM and IgG ELISA [26, 27]. Primary DENV infection was defined if the ratio of IgM to IgG was greater than or equal to 1.2, and secondary DENV infection was defined if it was less than 1.2 [27]. Patients who were younger than 16 years or who were diagnosed with DSS were excluded owing to incomplete data and inadequate patient number. Demographic, clinical, and laboratory data of the included patients were obtained from medical records 
beginning on the day of fever onset (defined as day 0 of the illness). Some adult patients $(14.8 \%)$ had one or more comorbid diseases that could have complicated the febrile course during the leukopenic period; therefore, we did not define defervescence as day 0 [23]. Fever was considered to have subsided if body temperature was less than $37.5^{\circ} \mathrm{C}$. Enrolled patients were divided into 3 groups according to disease severity, DF, DF with hemorrhage, and DHF, for observation of trends of laboratory parameters. DHF was diagnosed using the following WHO criteria: (1) plasma leakage syndrome with hemoconcentration (hematocrit $20 \%$ or more above baseline), pleural effusion, or ascites; (2) fever lasting 2-7 days; (3) thrombocytopenia (platelet count less than 100,000 cells $/ \mathrm{mm}^{3}$ ); and (4) hemorrhagic tendency, as demonstrated by a positive tourniquet test or spontaneous bleeding [1]. DF with hemorrhage was defined as DF with hemorrhagic presentation but no evidence of plasma leakage. Secondary DENV infection was associated with a more severe disease presentation [28]. Therefore, we also analyzed the relationship between laboratory data and primary/secondary infection status.

\section{Data Analysis}

Laboratory data are expressed as means \pm standard deviation (SD). Categorical data were compared using the $\chi^{2}$ test with or without the Fisher exact test. Continuous data were analyzed with analysis of variance (ANOVA) by SPSS 13.0 software (SPSS, Inc., Chicago, IL, USA). The Scheffe test was used to compare groups when ANOVA revealed significant differences. A 2-tailed test with $p<0.05$ was considered statistically significant.

\section{Co-Culture of DENV-Exposed Platelets with Monocytes}

Peripheral blood mononuclear cells (PBMCs) and platelets were obtained from healthy volunteers after they gave their written informed consent. Platelets were isolated from PBMC buffy coat by centrifugation in OptiPrep gradient as described previously [17]. CD14+ cells $\left(2 \times 10^{6}\right)$ were freshly isolated from the same PBMC buffy coat with magnetic beads (Miltenyi Biotech Inc., Auburn, CA, USA) Approximately $1 \times 10^{8}$ platelets were infected with DENV2 at MOI 0.3 or left uninfected, and then incubated with $2 \times 10^{6}$ isolated CD4+ cells. Mock and DENV-infected cells were collected and applied to slides at different time points after co-culture for immunofluorescent staining.

\section{Immunohistochemistry, Immunofluorescent Staining, and FACS Analysis}

Freshly prepared blood smears from acute dengue patients were used for the study. The antibodies used in this study were anti-CD61 antibody-conjugated with HRP (Miltenyi Biotech), mouse anti-E monoclonal antibody (clone 4G2), anti-histone 2A antibody conjugated with FITC (Santa Cruz Biothechnology Inc., Santa Cruz, CA, USA), and DyLight 594-conjugated horse anti-mouse IgG antibody (Vector Laboratories Inc., Burlingame, CA, USA). Immunohistochemical staining for the detection of platelets on the blood smear was performed by employing the Vectastain ABC immunohistochemistry kits (Vector Laboratories) according to the manufacturer's instructions. Following the primary antibody staining, the stained samples were incubated with diaminobenzidine as an enzyme substrate for peroxidase followed by counterstaining with hematoxylin. For the dengue viral antigen and histone $2 \mathrm{~A}$ staining of blood smears, slides were subjected to the immunofluorescent staining approach as previously described [10]. Images of the stained cells were captured with a Zeiss microscope equipped with an Axis 5 digital camera.

FACS Flow Cytometry Assay

FACS analysis and intracellular staining was performed as previously described [29]. Briefly, after harvesting of cells, which was followed by centrifugation at $300 \mathrm{~g}$ for $8 \mathrm{~min}$ and 
Table 1. Patient demographics and other characteristics

\begin{tabular}{|c|c|c|c|c|c|}
\hline & $\begin{array}{l}\text { Total } \\
(n=1,015)\end{array}$ & $\begin{array}{l}\text { DF } \\
(n=579)\end{array}$ & $\begin{array}{l}\text { DF with } \\
\text { hemorrhage } \\
(n=232)\end{array}$ & $\begin{array}{l}\text { DHF } \\
(n=204)\end{array}$ & $\begin{array}{l}p \\
\text { value }^{\mathrm{a}}\end{array}$ \\
\hline \multicolumn{4}{|l|}{ Gender } & $51.15 \pm 16.3$ & $0.05^{\mathrm{b}}$ \\
\hline Male & $482(47.5)$ & 277 (47.8) & $104(44.8)$ & $101(49.5)$ & \multirow[t]{2}{*}{0.6} \\
\hline Female & $533(52.5)$ & $302(52.2)$ & $128(55.2)$ & $103(50.5)$ & \\
\hline GOT > $200(\mathrm{IU} / \mathrm{L})$ & $106(10.4)$ & $43(7.4)$ & 30 (12.9) & 33 (16.2) & 0.001 \\
\hline GPT > $200($ IU/L) & $68(6.7)$ & $28(4.8)$ & $17(7.3)$ & $23(11.3)$ & 0.006 \\
\hline Chronic hepatitis C & $24(2.4)$ & $10(1.7)$ & $9(3.9)$ & $5(2.5)$ & 0.189 \\
\hline Chronic hepatitis B & $46(4.5)$ & $23(4.0)$ & $10(4.3)$ & $13(6.4)$ & 0.36 \\
\hline \multicolumn{6}{|l|}{ Serotype } \\
\hline DENV1 & $14 / 400(3.5)$ & $10 / 239(4.2)$ & $4 / 86(4.7)$ & $0 / 75(0)$ & \multirow[t]{4}{*}{$0.141^{\mathrm{c}}$} \\
\hline DENV2 & $294 / 400(73.5)$ & $178 / 239(74.5)$ & $58 / 86(67.4)$ & $58 / 75(77.3)$ & \\
\hline DENV3 & $91 / 400$ (22.8) & $51 / 239(21.3)$ & $24 / 86$ (27.9) & $16 / 75(21.3)$ & \\
\hline DENV4 & $1 / 400(0.3)$ & 0/239 (0) & $0 / 86(0)$ & $1 / 75(1.3)$ & \\
\hline Primary infection & $177 / 552(32.1)$ & $106 / 314(33.8)$ & $42 / 122(34.4)$ & $29 / 116(25.0)$ & 0.184 \\
\hline Secondary infection & $375 / 552(67.9)$ & $208 / 314(66.2)$ & $80 / 122(65.6)$ & $87 / 116(75.0)$ & \\
\hline
\end{tabular}

Values are presented as $n(\%)$ unless otherwise indicated. DF, dengue fever; DHF, dengue hemorrhagic fever; DENV, dengue virus. ${ }^{a} \chi^{2}$ test. ${ }^{b}$ One-way ANOVA. ${ }^{c}$ Fisher exact test.

resuspension in $100 \mu \mathrm{L}$ flow staining buffer (1\% FBS and $0.1 \% \mathrm{NaN}_{3}$ in PBS), desired antibodies were added to each tube according to the manufacturer's specifications and stained on ice for $1 \mathrm{~h}$ with no exposure to light. Staining buffer was then added to each tube, and the tubes were centrifuged at $300 \mathrm{~g}$ for $8 \mathrm{~min}$ to wash the excess antibodies, with this process being repeated 3 times. Cells were then resuspended in $300 \mu \mathrm{L}$ to $1 \mathrm{~mL}$ of flow staining buffer, depending on the number of cells. Data was collected and analyzed using $2 \times 2$ quadrant methods to obtain each individual subpopulation.

\section{Generation of Heat Maps}

PBMCs were stained and processed using a BD LSRFortessa ${ }^{\mathrm{TM}}$ flow cytometer (Bectin, Dickinson and Company, Franklin Lakes, NJ, USA). FACS data were analyzed using Kaluza software version 1.3 (Beckman Coulter, Brea, CA, USA). Microsoft Excel version 10 (Microsoft Corporation, Redmond, WA, USA) was used to create templates compatible with the heat map illustrator. All templates included within the expression of collected cell subsets found in each donor were imported to HemI Heatmap Illustrator version 1.0.3.3 for generation of heat maps (http://hemi.biocuckoo.org/). All heat map images were enhanced with additional related information and descriptions to create a complete figure using Windows Accessories Tool Paint (Microsoft).

\section{Results}

Demographic of Patient Characteristics

A total of 1,015 patients who survived with acute DENV infections (male-to-female ratio, 1:1.11; mean age, $48.8 \pm 15.8$ years) were enrolled for analysis (Table 1 ). We did not find any gender differences in disease severity $(p=0.584)$ in DENV infections as previously reported 


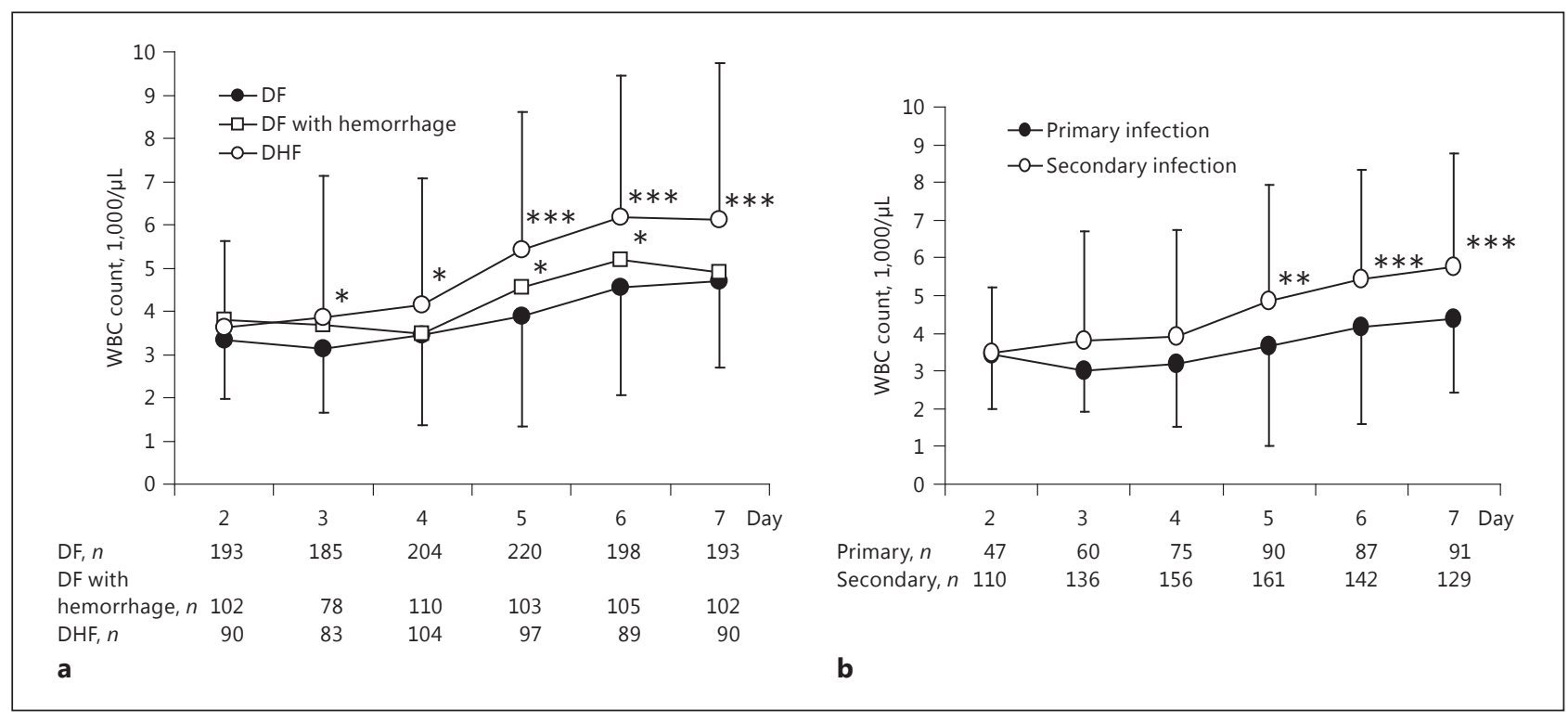

Fig. 1. Kinetic changes in leukocyte (white blood cell [WBC]) count. a Dengue virus (DENV) infection caused leukopenia with the lowest WBC count found in dengue fever (DF) patients, higher in DF patients with hemorrhage, and highest in dengue hemorrhagic fever (DHF) patients. b WBC counts were higher in patients with secondary infection than primary infection on days 5-7. Two-way ANOVA with the Scheffe test was used for statistical analysis. Asterisks designate statistical significance levels: ${ }^{*} p<0.05,{ }^{* *} p<0.01$, and ${ }^{* * *} p<0.001$.

[24]. Patients with DHF were older and more frequently had high GOT and/or GPT levels ( $>200 \mathrm{IU} / \mathrm{L}$ ) than DF subjects (Table 1). Most of the patients were infected with DENV2 (73.5\%) followed by DENV3 (22.8\%), and thus only DENV2- and DENV3-infected patients were subjected to further analysis. The distribution of serotypes was not different among the 3 groups (i.e., patients with DF, DF with hemorrhage, and DHF), and secondary DENV infection was not associated with the occurrence of DHF (Table 1). However, an association with the occurrence of DHF by comparing DF with/without hemorrhage and DHF ( $p=0.022)$ was noticed.

\section{Kinetics of Leukocyte Counts after Fever Onset}

Detailed measurements of the daily parameters after fever onset are shown in online supplementary Table 1 (see www.karger.com/doi/10.1159/000457785 for all online suppl. material). The earliest day on which we could have dengue patients enrolled for the current study was day 2 after fever onset. The kinetics for the key parameters during the febrile period are presented as figures.

The best known change in dengue patients is the white blood cell (WBC) count; hence, this was the first thing we looked at. The kinetics of WBC during the febrile period was lowest on day 3 in patients with DF and on day 4 in patients with DF and hemorrhage (Fig. 1a). However, the nadir WBC count came earlier (on day 2), and the WBC count was higher in patients with DHF than in those with DF. Patients with DHF and those with DF and hemorrhage had an unusual increase in WBC count on days 5 and 6 (Fig. 1a). Leukocyte counts were also higher on days 5-7 in patients with secondary infection than those with primary infection (Fig. 1b). Interestingly, transient monocytosis (monocyte surge) was not found in DF patients or those with DF with hemorrhage, even though the absolute monocyte count of DHF patients 

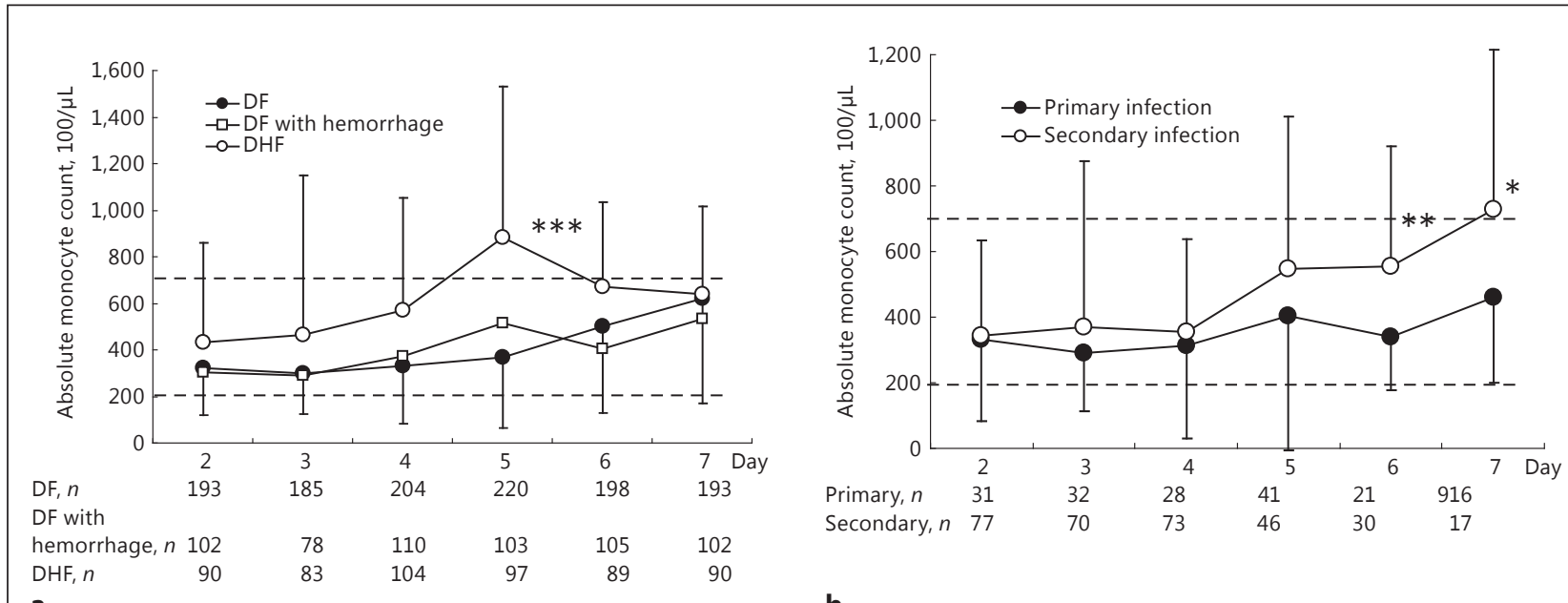

a

b
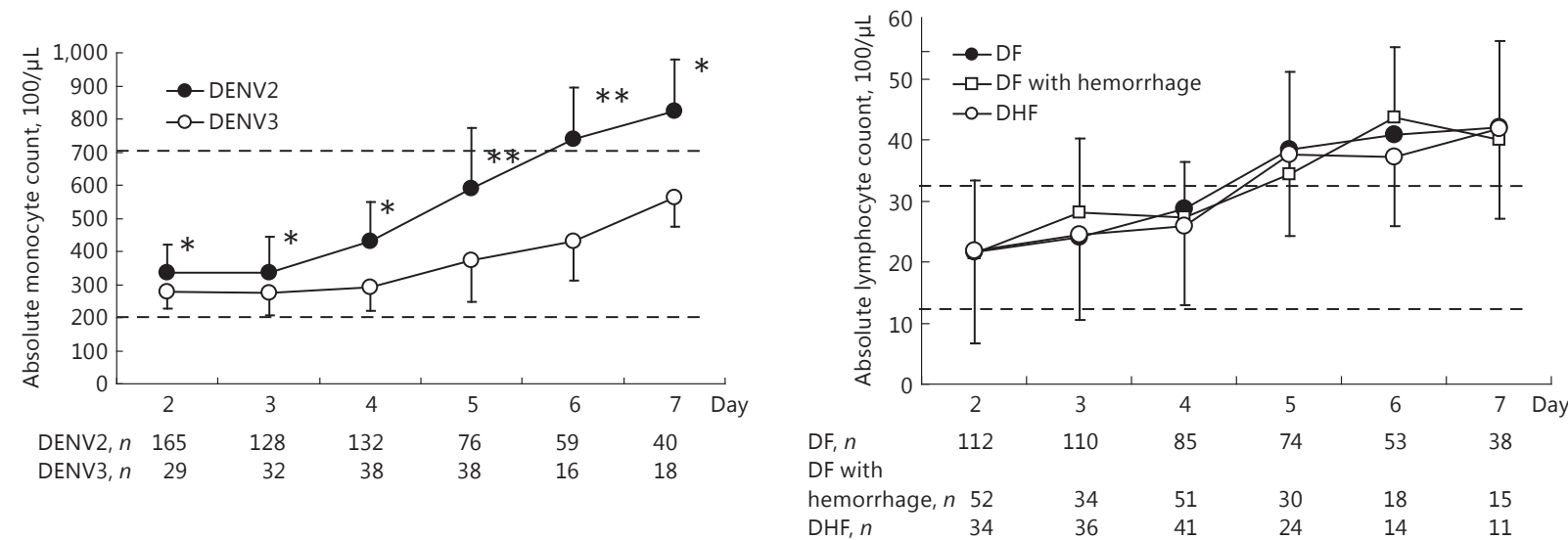

c

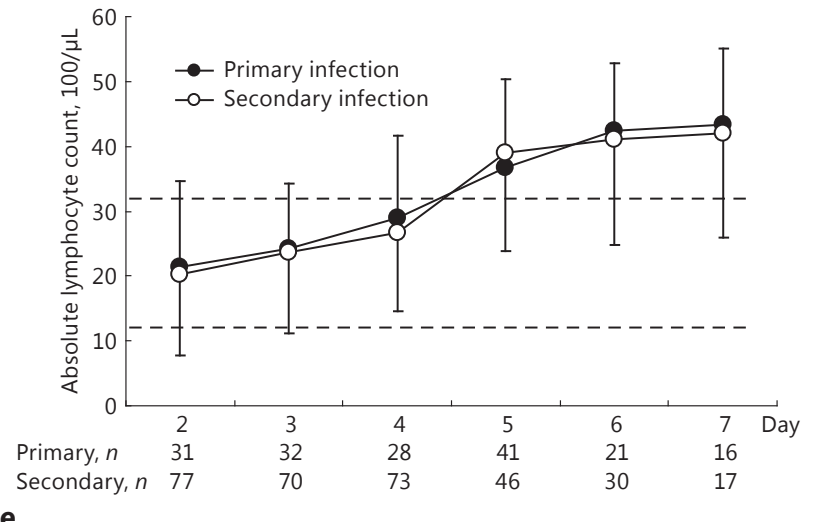

d

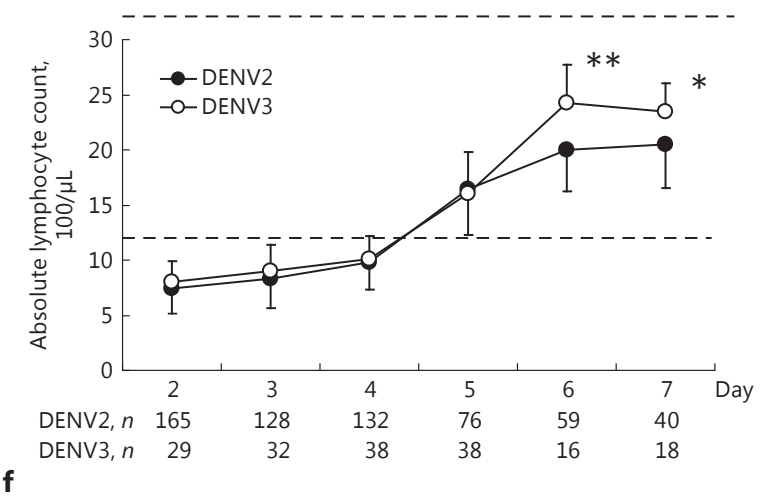

Fig. 2. Kinetic changes in absolute monocyte count and lymphocyte count. a The monocyte count in patients with dengue hemorrhagic fever (DHF) surged on day 5. b In comparison to patients with primary dengue, absolute monocyte count in patients with secondary infection increased on day 5 , and became statistically significant on days 6-7. Absolute monocyte count was increased to a greater extent by dengue virus type-2 (DENV2) infection than by DENV3 infection (c), while lymphocyte count was increased to a greater extent by DENV3 than DENV2 infection after day 6 (f). Absolute lymphocyte count increased progressively in all patient groups (d) and showed no difference between primary and secondary dengue infections (e). Two-way ANOVA with the Scheffe test was used for statistical analysis. The normal range of the cell counts is outlined between the dashed lines. Asterisks designate statistical significance levels: ${ }^{*} p<0.05,{ }^{* *} p<0.01$, and ${ }^{* * *} p<0.001$. 


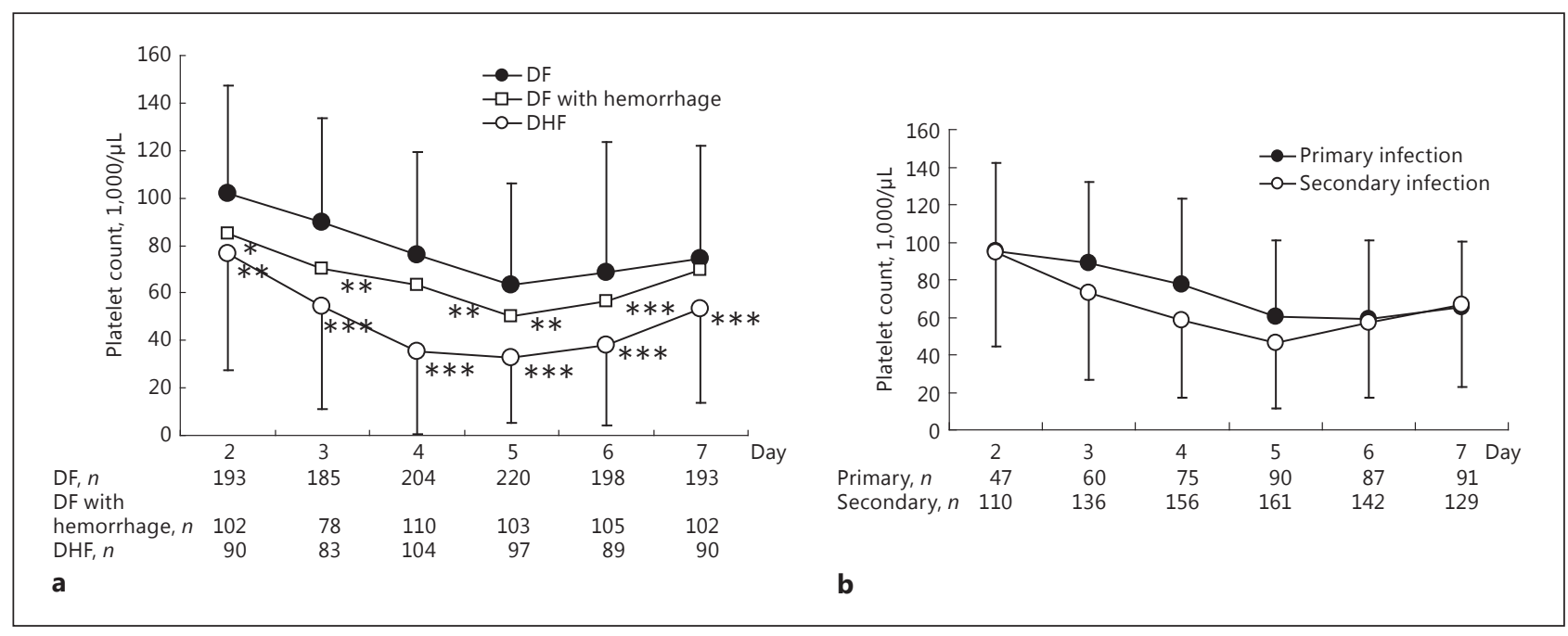

Fig. 3. Kinetic changes in platelet count. Recovery from thrombocytopenia was incomplete during the first week after onset of fever. a Dengue virus (DENV) infection caused more severe thrombocytopenia in dengue hemorrhagic fever (DHF) patients or dengue fever (DF) patients with hemorrhage than those with DF only. b Platelet counts were not different between primary and secondary infections. In order to avoid an interference of the visual effect on the graph, the DF line was presented as an average instead. Two-way ANOVA with the Scheffe test was used for statistical analysis. Asterisks designate statistical significance levels: $*^{*}<0.05$, ** $p<0.01$, and ${ }^{* * *} p<0.001$.

had a surge on day 5 (Fig. 2a). Moreover, the absolute monocyte count seemed to increase on days 6 and 7 in patients with secondary infection, but not in patients with primary infection (Fig. 2b). We also observed higher monocyte counts in DENV2 infection than in DENV3 infection, especially after day 5 (Fig. 2c). Although absolute lymphocyte count increased after day 5 (Fig. 2d-f), there was no difference observed among the clinical groups (Fig. 2d) or between primary and secondary infection (Fig. 2e). Nevertheless, DENV3 infection might have induced higher lymphocyte count on days 6 and 7 (Fig. 2f).

\section{Kinetics of Platelet Count and aPTT after Fever Onset}

Platelet dysfunctions and thrombocytopenia are common in DENV-infected patients. The platelet counts were lower in those with more severe disease (Fig. 3a). We observed the amounts of platelets at its nadir on day 5 , which appeared to be gradually recovered on day 7 after fever onset. In addition, the platelet counts were similar between primary and secondary DENV infection in patients (Fig. 3b). Interestingly, in general, patients usually had prolonged plasma aPTT, but aPTT was significantly longer in patients with DHF than those with DF (Fig. 4a). Secondary DENV infection was also associated with prolonged aPTT (Fig. 4b).

\section{Laboratory Measurements in Dengue Patients}

The levels of hemoglobin $(\mathrm{Hb})$ in patients with DHF were slightly higher on day 4, but dropped lower on day 7, compared to patients with DF and DF with hemorrhage patients, who seemed to have little change during the febrile stage (Fig. 5a). Interestingly, we observed that secondary DENV infection was associated with a lower $\mathrm{Hb}$ level after day 6 compared to primary DENV infection (Fig. 5b). In addition, we found that $\mathrm{Hb}$ level was similar in DENV2and DENV3-infected patients during the febrile period (Fig. 5c). 


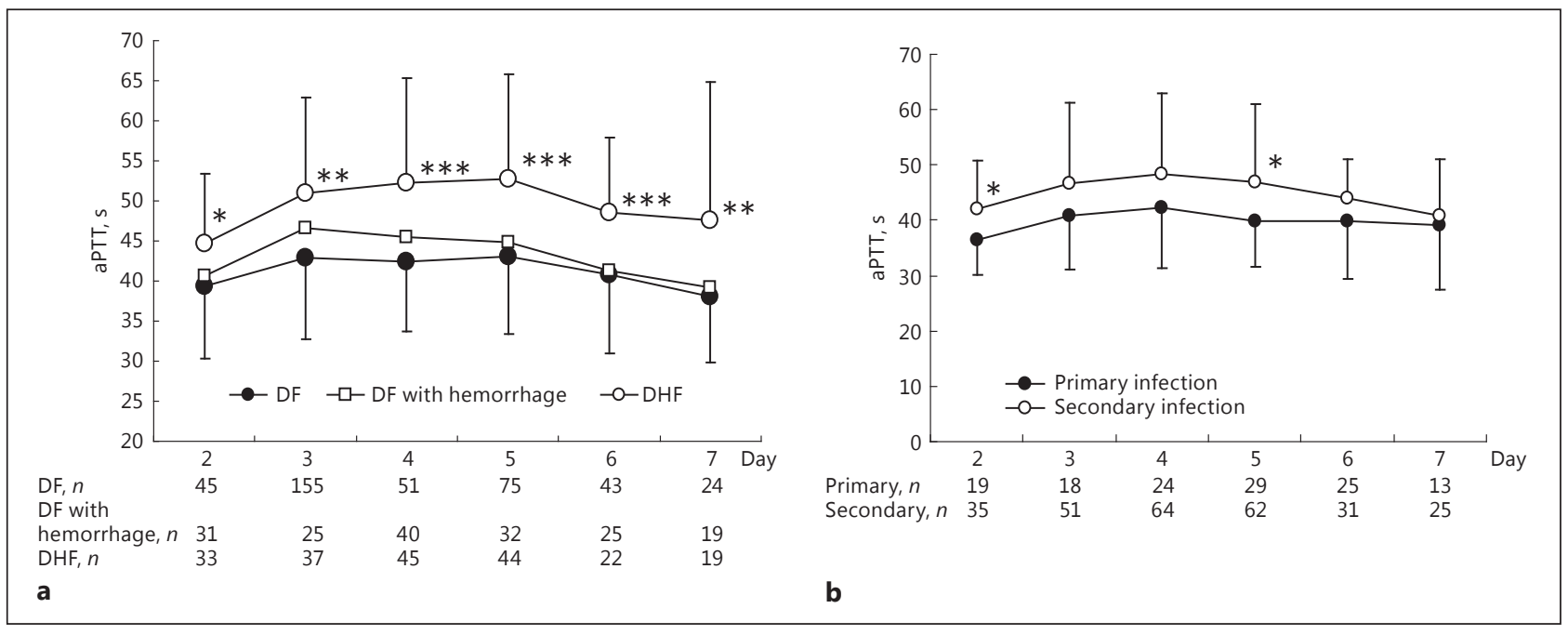

Fig. 4. Kinetic changes in activated partial thromboplastin time (aPTT) after infection. a aPTT was significantly prolonged in patients with dengue hemorrhagic fever (DHF) after day 2 of febrile episode and peaked on day 5. b The aPTT level in patients with secondary infection was more prolonged than that with primary infection. Two-way-ANOVA with the Scheffe test was used for statistical analysis. Asterisks designate statistical significance levels: $* p<0.05{ }^{* *} p<0.01$, and ${ }^{* * *} p<0.001$.

As a whole, an intimate relationship between platelet counts and absolute monocyte counts was observed during the period of febrile stage. The lowest level of platelets corresponded to the sudden surge of monocytes on day 5 after fever onset (Fig. 6a). Coincidentally, IL-10, an anti-inflammatory cytokine, was found to be highest on day 5 (Fig. 6b). Further analysis of a new set of confirmed dengue specimens (see online suppl. Table 1) during a recent dengue epidemic in Taiwan revealed that inflammatory monocytes were seen at higher levels during the early phase of fever and declined over time, and that the majority of activated platelets were aggregated with CD14+ monocytes (Fig. 6c-e). In contrast, fluctuating levels of myeloid dendritic cells and plasmacytoid dendritic cells were observed (Fig. 6c, d, and online suppl. Fig. 1 and 2) and that these cells were less likely to be associated with activated platelets (Fig. 6e). This is in line with previous reports that activated platelets dominantly aggregated with monocytes during the late febrile period [29], and DENV infections induced the phenotype of inflammatory monocytes in PBMCs of dengue patients [30]. To further address the observed phenomenon, an ex vivo experiment was performed.

\section{DENV-Infected Platelets and Co-Cultured with PBMC Monocytes}

It has been previously demonstrated that the platelet-monocyte aggregates (PMA) were the most frequent event in acute dengue samples [29]. With evidence suggesting platelets can be infected by DENV and become activated $[17,18,31]$, an ex vivo study was carried out to verify the DENV-infected platelets, which could be aggregated with monocytes directly. Platelets were purified and infected with DENV as previously described [8]. After washing out unbound virus, the DENV platelets were mixed with allogeneic PBMCs for the indicated times specified in the online supplementary figure legends. DENV-PMA were observed for $10 \mathrm{~min}$ after being cocultured (Fig. 6f), while very scarce PMA were observed when uninfected platelets were co-cultured with allomonocytes (Fig. 6g). Interestingly, the DENV-PMA were gradually internalized at $24 \mathrm{~h}$ (online suppl. Fig. 3a, $24 \mathrm{~h}$ ), and the DENV-PMA were completely inside the cytoplasm of monocytes at $48 \mathrm{~h}$ after being co-cultured (online suppl. Fig. $3 \mathrm{~b}, 48 \mathrm{~h}$ ). The identification 


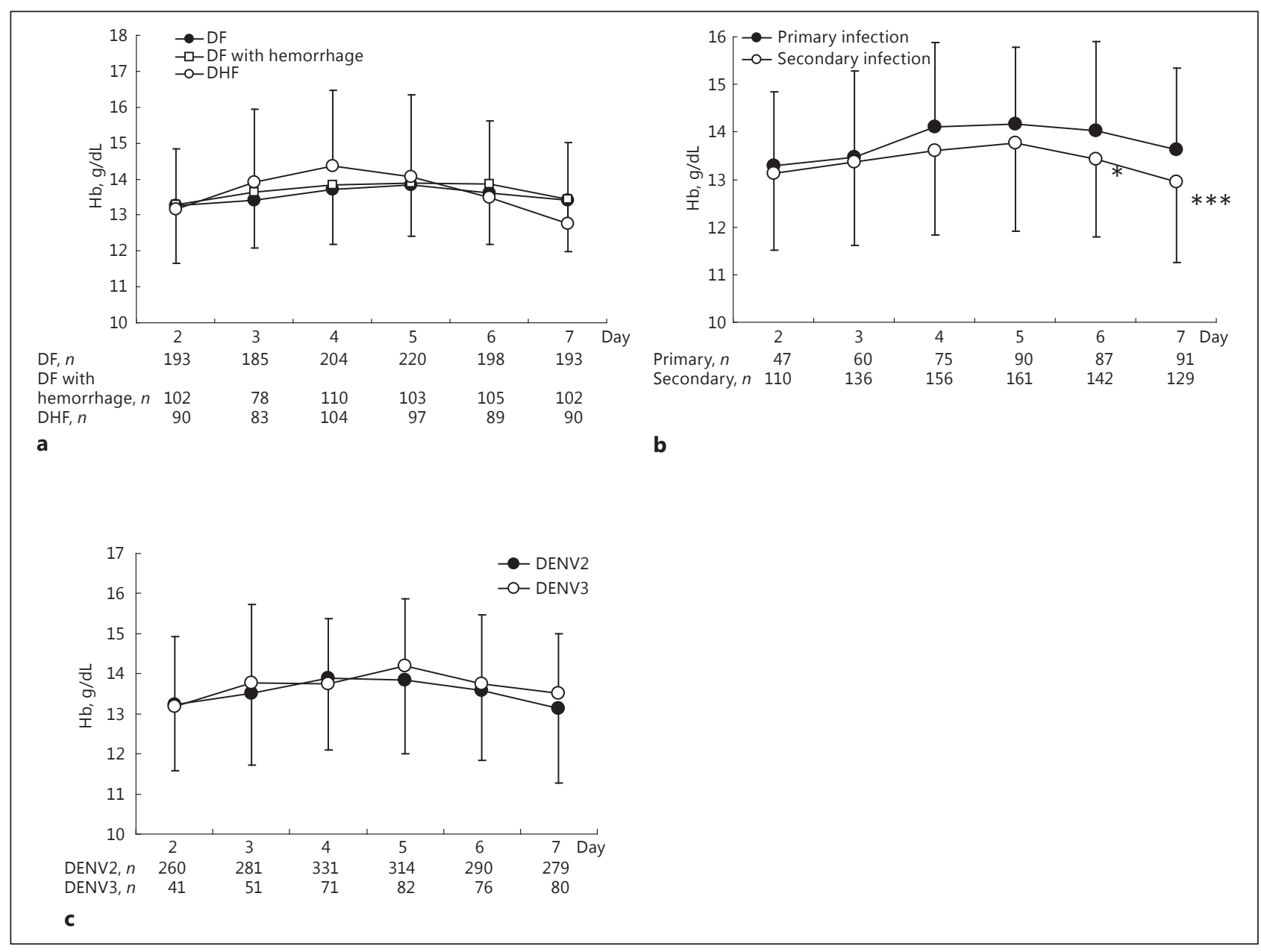

Fig. 5. Kinetic changes in hemoglobin ( $\mathrm{Hb})$. a, c $\mathrm{Hb}$ level did not depend on disease severity or serotype of dengue virus (DENV) infection. b Patients with secondary infection had lower Hb levels on days 6 and 7 than those with primary infection. Two-way ANOVA with the Scheffe test was used for statistical analysis. Asterisks designate statistical significance levels: ${ }^{*} p<0.05$, ${ }^{* *} p<0.01$, and ${ }^{* * *} p<0.001$.

of DENV-PMA was further confirmed with immunofluorescence staining with DENV-specific 3H5 monoclonal antibody (online suppl. Fig. 3c). The fate of the monocytes was evaluated by FACS after $48 \mathrm{~h}$ of co-cultivation. Two major populations of monocytes were observed, designated as G1 and G2 (online suppl. Fig. 4a). An increase of monocyte granularity was observed, as was a shift to the size of the monocytes after the co-cultivation of DENV-platelets with monocytes (online suppl. Fig. 4a). Surface markers, such as DC-SIGN and HLA-DR, were found to be increased in the DENV-PMA group in both G1 and G2 populations (online suppl. Fig. 4b, c). In contrast, downregulation of CD14 marker was noticed in the PMA group (online suppl. Fig. 5).

\section{Discussion}

Our data demonstrated that adult patients with DF had lower platelet counts, prolonged aPTT, and transient monocytosis on day 5, the time period with the greatest risk for developing DHF [32]. One of the salient clinical features in dengue patients is abnormal hemostasis, 


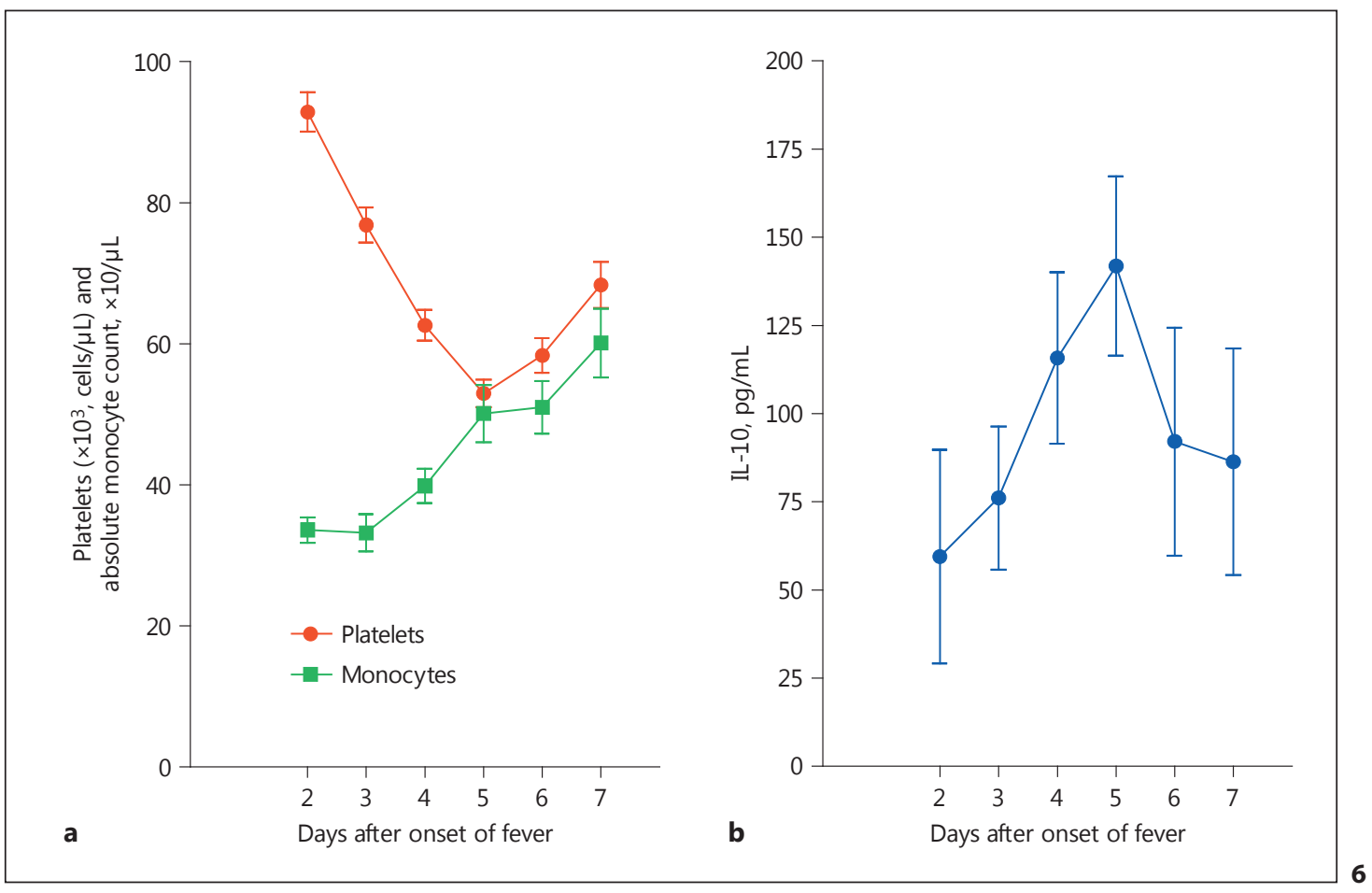

(Figure continued on next pages.)

for instance increased vascular permeability, thrombocytopenia, impaired platelet function, and in some of severe conditions, disseminated intravascular coagulation, contributing to dynamic of bleeding tendency [33]. Interestingly, although patients with DHF have plasma leakage and bleeding tendency, subjects with thrombocytopenia and prolonged aPTT did not inevitably have bleeding. Moreover, an acquired platelet dysfunction early in DHF patients prior to thrombocytopenia was demonstrated by Mitrakul et al. [34] in 1977 and by Srichaikul et al. [35] in 1989. As such, if patients could be protected from bleeding around day 5, the risk of developing DHF might be decreased. Plasma leakage caused hemoconcentration with elevated $\mathrm{Hb}$, but bleeding induced anemia. Not surprisingly, we found an initial modest increase of $\mathrm{Hb}$ in patients with DHF. However, these effects could counteract each other and obscure the differences in $\mathrm{Hb}$ change between the DHF and DF groups.

Activated platelets harboring DENV have been demonstrated to form an aggregation with monocytes during the critical stage of illness [29], suggesting a likely role of viral clearance and a cause of thrombocytopenia implemented by phagocytic innate immune cells $[36,37]$. Although DENV infection of monocytes/macrophages is very inefficient $[10,16,38]$, the severity of DENV infection has been linked to the number of DENV antigen-positive monocytes and their increased activation [39]. A sequential cascade of events including low platelet counts and prolonged aPTT coupled with transient monocytosis, enhancing phagocytic activity during the course of DENV infection, may result in releasing a large amount of soluble factors to induce DHF [3]. Therefore, the dysfunctional platelets in conjunction with transiently activated monocytosis could be a key event in the pathogenesis of developing DHF after DENV infection.

We also found that WBC kinetics is different between DHF adults and DHF children reported previously. Nimmannitya et al. [24] showed the lowest mean WBC counts $(7,000 /$ $\mu \mathrm{L}$ ) on day 3 in 35 DHF children, while we found the nadir of the WBC count (mean 3,500/ $\mu \mathrm{L}$ ) on day 2 , one day earlier than in children. Additionally, the total lymphocyte count of these 

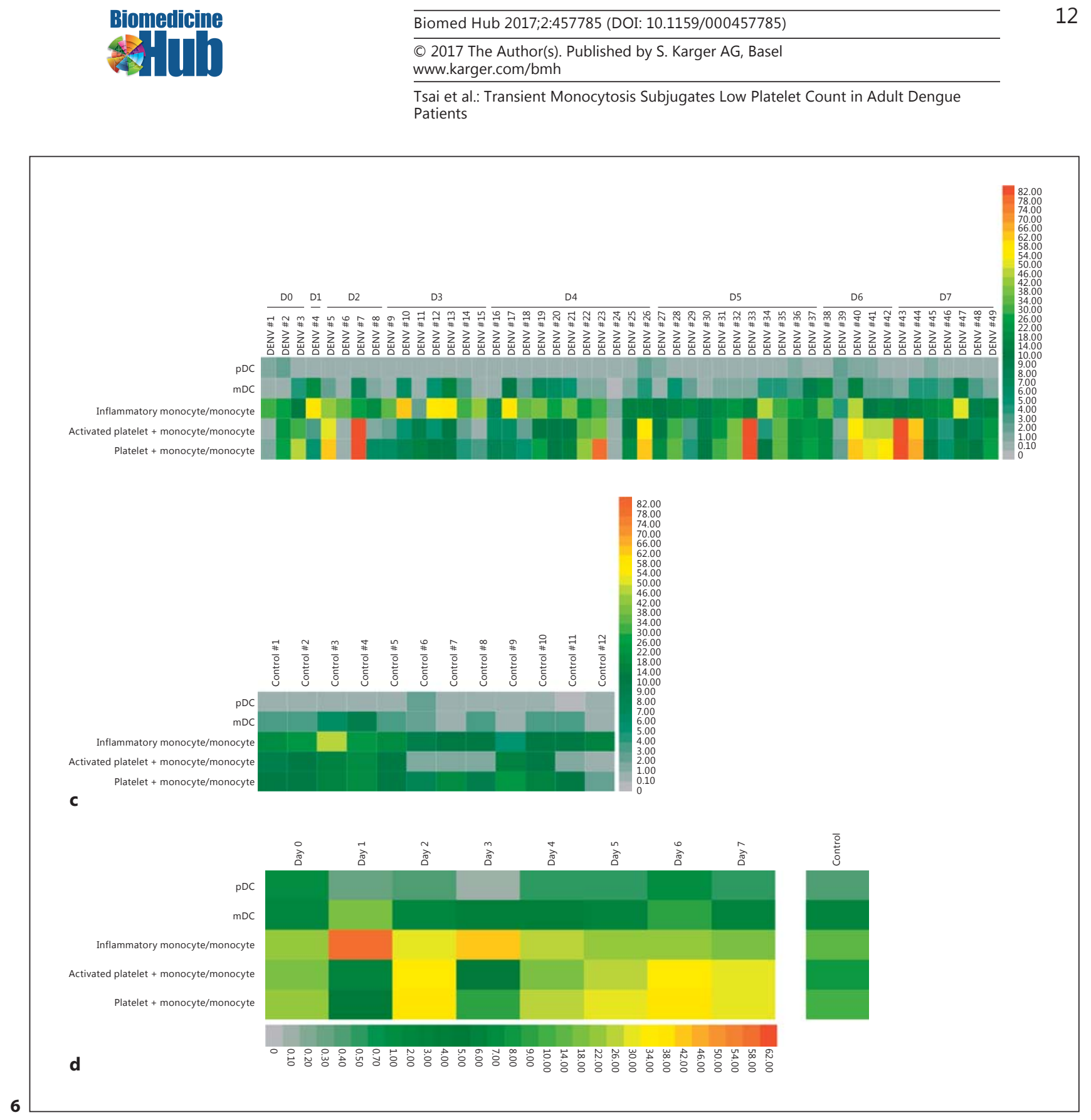

(Figure continued on next pages.)

children reached its nadir on day 4 with a mean value of $4,000 / \mu \mathrm{L}$ [24], whereas our adult patients reached the nadir on day 2 , with the mean value of $2,200 / \mu \mathrm{L}$. Hence, adult dengue patients had more serious leukopenia than children. Furthermore, Nimmannitya et al. [24] did not report transient monocytosis in dengue-infected children, suggesting the changes of lymphocyte and monocyte counts might be regulated by different mechanisms during dengue viral infections in adults and in children. These salient features could hint at an important difference in clinical manifestations between children and adult patients.

Thrombocytopenia is a universal clinical finding in patients infected with DENV [1]. Immune-mediated destruction of platelets [40, 41], platelet consumption caused by high levels of platelet-activating factor released from monocytes [42], direct infection by DENV $[17,18,31]$, and activated platelets phagocytosis by monocytes $[29,43,44]$ have been implicated. Current results have shown a decrease in platelet count on day 2 after fever onset in all of our patients, even though the lowest count was seen on day 5 in patients with DHF. As 
Tsai et al.: Transient Monocytosis Subjugates Low Platelet Count in Adult Dengue Patients

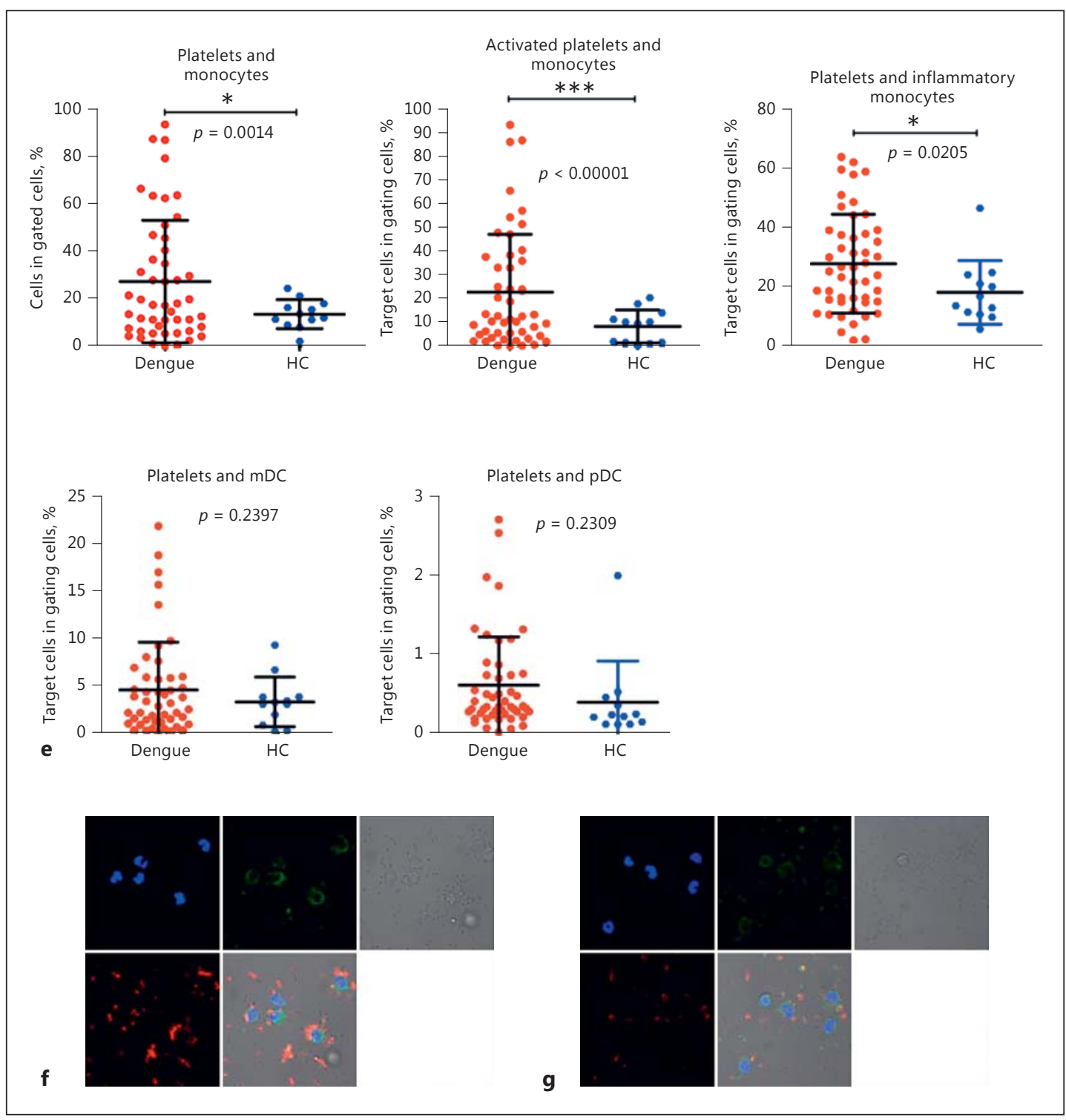

Fig. 6. Platelet downward counts corresponded to a sudden upward surge of monocytes in peripheral blood of dengue patients. Platelet and monocytes counts were performed with a standard cell counter and tabulated as days after onset of fever. a The platelet count was higher at an early febrile stage and gradually decreased to the nadir on the 5th day of fever, and rebounded in an upward scenario, while the absolute count of monocytes dramatically increased on day 4 and onward within the observed period. b Anti-inflammatory cytokine IL-10. The levels of IL-10 was gradually increased and peaked on day 5, and decreased afterward. c Profiling status of phagocytic cells in peripheral blood mononuclear cells. The antibodies utilized for the FACS analysis and the gated strategies to differentiate the target populations were previously described [24]. Kinetically, the majority of platelet-monocyte aggregates were in the category of activated platelet-monocytes. In contrast, the levels of inflammatory monocytes were higher during early fever days, and gradually subsidized at a late period of fever. Both the levels of myeloid dendritic cells (mDC) and plasmacytoid dendritic cells ( $\mathrm{pDC}$ ) were very similar to that of control subjects. d Average profile of phagocytic cells in peripheral blood mononuclear cells. e Platelet-monocyte aggregates were significantly increased in dengue patients. Activated platelets were significantly aggregated with monocytes compared to that of myeloid dendritic cells and plasmacytoid dendritic cells. f, g DENV-activated platelets engulfed by monocytes. DENV-activated platelets were co-cultured with monocytes as described in the Methods. $\mathbf{f}$ DENV-activated platelets were engulfed by monocytes after $10 \mathrm{~min}$ of co-cultured. $\mathbf{g}$ Uninfected platelets were hardly seen to be engulfed by monocytes. Red: DENV-infected platelets; green: CD14 marker; blue: DAPI nucleus staining. 
such, a hypothetical scenario can be drawn: activated platelets may be engulfed by a transient surge of monocytes on day 5 in patients with DF, contributing to thrombocytopenia as reported previously [42]. The prolonged aPTT is a sign of dysfunctional platelets, likely a result of DENV infection [17, 18, 22, 31]. Hence, lack of difference in thrombocytopenia between patients with primary and secondary infections might suggest that it is mediated by a nonadaptive immune mechanism, for example a consequence of DENV infection. In addition, sample size difference may contribute to the observed timing for the lowest thrombocyte count in current study being different from that of previous reports. Nimmannitya et al. [24] showed the lowest platelet count during day 6 and day 8 , with mean values over $120,000 / \mu \mathrm{L}$ in 35 DHF children. Huang et al. [45] found that the platelet count nadir occurred on day 8, not day 6, in 8 adults and children with DHF/DSS. Our larger adult patients had thrombocytopenia at the nadir levels on day 5 with a mean value of $32,000 / \mu \mathrm{L}$. In addition, by comparison, adult DHF patients had more serious thrombocytopenia than dengue-infected children. Patients with DHF had both the lowest platelet count and highest aPTT on day 5, which might render them the most likely to have bleeding episodes after day 5 [1]. However, bleeding episodes depend on several factors, including vasculopathy, thrombocytopenia, platelet capacity, prothrombin-complex deficiency, and dengue viral NS1 protein [46]. Experimental ex vivo investigations revealed that platelets upon exposure to DENV enhanced the capacity of engulfment by monocytes, which altered the phenotypes toward macrophages or dendriticlike cells after the phagocytosis of the DENV-activated platelets. These results suggest that phagocytic immune cells play a critical role in restriction of viral dissemination and in thrombocytopenia in affected dengue patients.

In summary, adult DHF patients had low platelet counts, prolonged aPTT, and a transient monocytosis on day 5. Our results were different from reports tabulated from children with DHF. Uniquely, our data suggest that transient monocytosis coupled with low and dysfunctional platelets might enhance the cytokine storm-induced endothelial cell damage and potentiate the plasma leakage, and thus could be a key factor in the development of DHF.

\section{Acknowledgements}

This research was, in part, supported by the Ministry of Health and Welfare (MOHW104CDC-C-114-114901) (J.J.T.) and Ministry of Education, Taiwan, ROC. The Aim for the Top University Project to the National Cheng Kung University (NCKU), and Ministry of Science and Technology Grant (NSC 102-2320-B-006-049 and MOST 103-2320-B-006-030-MY3) (G.C.P.). The authors also would like to thank Dr. Sansanee Noisakran at the Division of Dengue Hemorrhagic Fever Unit, Department of Research and Development, Faculty of Medicine Siriraj Hospital, Mahidol University, Bangkok, Thailand, for her expert guidance in FACS analysis.

\section{Ethics Statement}

The studied subjects (or their parents or guardians) have given their informed written consent and the study protocol was approved by an appropriate ethics committee; the institutional review board (IRB) of Kaohsiung Medical University Hospital (KMUH) and IRB of National Cheng Kung University with approval protocol No. 960195 and protocol No. B-ER104-178. All patients could only be identified by numbers or aliases, not by their real names. 


\section{Disclosure Statement}

There were no potential conflicts of interest relevant to this article.

\section{Author Contributions}

Jih-Jin Tsai designed the experiments and final approval of the version to be published; Jung-San Chang wrote the draft of the article; Chao-Ching Wang performed retrospective data analysis; Ko Chang, Wei-Ru Lin, and Li-Teh Liu collected and acquired data; Tzu-Chuan Ho and Sia Seng Tan performed FACS analysis and cytokine assay; Yu-Wen Chien assisted with the institutional review board protocol and recruitment; Yu-Chih Lo performed IFA studies and discussed the interpretation of the results; Guey Chuen Perng wrote and edited the manuscript.

\section{References}

Global Strategy for Dengue Prevention and Control 2012-2020. Geneva, WHO, 2012.

2 Bhatt S, Gething PW, Brady OJ, Messina JP, Farlow AW, Moyes CL, Drake JM, Brownstein JS, Hoen AG, Sankoh O, Myers MF, George DB, Jaenisch T, Wint GR, Simmons CP, Scott TW, Farrar JJ, Hay SI: The global distribution and burden of dengue. Nature 2013;496:504-507.

-3 Guzman MG, Harris E: Dengue. Lancet 2015;385:453-465.

-4 Coffey LL, Mertens E, Brehin AC, Fernandez-Garcia MD, Amara A, Despres P, Sakuntabhai A: Human genetic determinants of dengue virus susceptibility. Microbes Infect 2009;11:143-156.

5 Rico-Hesse R: Dengue virus markers of virulence and pathogenicity. Future Virol 2009;4:581.

6 John DV, Lin YS, Perng GC: Biomarkers of severe dengue disease - a review. J Biomed Sci 2015;22:83.

7 Noisakran S, Perng GC: Alternate hypothesis on the pathogenesis of dengue hemorrhagic fever (DHF)/dengue shock syndrome (DSS) in dengue virus infection. Exp Biol Med (Maywood) 2008;233:401-408.

-8 Tsai J-J, Liu L-T, Chang K, Wang S-H, Hsiao H-M, Clark KB, Perng GC: The importance of hematopoietic progenitor cells in dengue. Ther Adv Hematol 2012;3:59-71.

-9 Halstead SB, O’Rourke EJ, Allison AC: Dengue viruses and mononuclear phagocytes. II. Identity of blood and tissue leukocytes supporting in vitro infection. J Exp Med 1977;146:218-229.

10 Kou Z, Quinn M, Chen H, Rodrigo WW, Rose RC, Schlesinger JJ, Jin X: Monocytes, but not T or B cells, are the principal target cells for dengue virus (DV) infection among human peripheral blood mononuclear cells. J Med Virol 2008;80:134-146.

11 Scott RM, Nisalak A, Cheamudon U, Seridhoranakul S, Nimmannitya S: Isolation of dengue viruses from peripheral blood leukocytes of patients with hemorrhagic fever. J Infect Dis 1980;141:1-6.

12 Gubler DJ: Dengue and dengue hemorrhagic fever. Clin Microbiol Rev 1998;11:480-496.

-13 Russell PK, Halstead SB: Challenges to the design of clinical trials for live-attenuated tetravalent dengue vaccines. PLoS Negl Trop Dis 2016;10:e0004854.

14 Chen ST, Lin YL, Huang MT, Wu MF, Cheng SC, Lei HY, Lee CK, Chiou TW, Wong CH, Hsieh SL: CLEC5A is critical for dengue-virus-induced lethal disease. Nature 2008;453:672-676.

15 Miller JL, deWet BJ, Martinez-Pomares L, Radcliffe CM, Dwek RA, Rudd PM, Gordon S: The mannose receptor mediates dengue virus infection of macrophages. PLoS Pathog 2008;4:e17.

-16 Tassaneetrithep B, Burgess TH, Granelli-Piperno A, Trumpfheller C, Finke J, Sun W, Eller MA, Pattanapanyasat K, Sarasombath S, Birx DL, Steinman RM, Schlesinger S, Marovich MA: DC-SIGN (CD209) mediates dengue virus infection of human dendritic cells. J Exp Med 2003;197:823-829.

-17 Noisakran S, Gibbons RV, Songprakhon P, Jairungsri A, Ajariyakhajorn C, Nisalak A, Jarman RG, Malasit P, Chokephaibulkit K, Perng GC: Detection of dengue virus in platelets isolated from dengue patients. Southeast Asian J Trop Med Public Health 2009;40:253-262.

18 Simon AY, Sutherland MR, Pryzdial EL: Dengue virus binding and replication by platelets. Blood 2015;126: 378-385.

-19 Noisakran S, Onlamoon N, Songprakhon P, Hsiao H-M, Chokephaibulkit K, Perng GC: Cells in dengue virus infection in vivo. Adv Virol 2010;2010:164878.

20 Noisakran S, Onlamoon N, Hsiao HM, Clark KB, Villinger F, Ansari AA, Perng GC: Infection of bone marrow cells by dengue virus in vivo. Exp Hematol 2012;40:250-259 e254.

21 Clark KB, Noisakran S, Onlamoon N, Hsiao HM, Roback J, Villinger F, Ansari AA, Perng GC: Multiploid CD61+ cells are the pre-dominant cell lineage infected during acute dengue virus infection in bone marrow. PLoS One 2012;7:e52902. 
22 Hsu AY, Wu SR, Tsai JJ, Chen PL, Chen YP, Chen TY, Lo YC, Ho TC, Lee M, Chen MT, Chiu YC, Perng GC: Infectious dengue vesicles derived from CD61+ cells in acute patient plasma exhibited a diaphanous appearance. Sci Rep 2015;5:17990.

-23 Kalayanarooj S, Vaughn DW, Nimmannitya S, Green S, Suntayakorn S, Kunentrasai N, Viramitrachai W, Ratanachu-eke S, Kiatpolpoj S, Innis BL, Rothman AL, Nisalak A, Ennis FA: Early clinical and laboratory indicators of acute dengue illness. J Infect Dis 1997;176:313-321.

24 Nimmannitya S, Halstead SB, Cohen SN, Margiotta MR: Dengue and chikungunya virus infection in man in Thailand, 1962-1964. I. Observations on hospitalized patients with hemorrhagic fever. Am J Trop Med Hyg 1969;18:954-971.

25 Lin CC, Huang YH, Shu PY, Wu HS, Lin YS, Yeh TM, Liu HS, Liu CC, Lei HY: Characteristic of dengue disease in Taiwan: 2002-2007. Am J Trop Med Hyg 2010;82:731-739.

26 Huang JH, Liao TL, Chang SF, Su CL, Chien LJ, Kuo YC, Yang CF, Lin CC, Shu PY: Laboratory-based dengue surveillance in Taiwan, 2005: a molecular epidemiologic study. Am J Trop Med Hyg 2007;77:903-909.

-27 Shu PY, Chen LK, Chang SF, Yueh YY, Chow L, Chien LJ, Chin C, Lin TH, Huang JH: Comparison of capture immunoglobulin $\mathrm{M}(\mathrm{IgM})$ and IgG enzyme-linked immunosorbent assay (ELISA) and nonstructural protein NS1 serotype-specific IgG ELISA for differentiation of primary and secondary dengue virus infections. Clin Diagn Lab Immunol 2003;10:622-630.

28 Halstead SB: Dengue. Lancet 2007;370:1644-1652.

29 Tsai JJ, Jen YH, Chang JS, Hsiao HM, Noisakran S, Perng GC: Frequency alterations in key innate immune cell components in the peripheral blood of dengue patients detected by FACS analysis. J Innate Immun 2011;3: 530-540.

-30 Kwissa M, Nakaya HI, Onlamoon N, Wrammert J, Villinger F, Perng GC, Yoksan S, Pattanapanyasat K, Chokephaibulkit K, Ahmed R, Pulendran B: Dengue virus infection induces expansion of a CD14(+)CD16(+) monocyte population that stimulates plasmablast differentiation. Cell Host Microbe 2014;16:115-127.

31 Noisakran S, Chokephaibulkit K, Songprakhon P, Onlamoon N, Hsiao HM, Villinger F, Ansari A, Perng GC: A re-evaluation of the mechanisms leading to dengue hemorrhagic fever. Ann NY Acad Sci 2009;1171(suppl 1):E24-E35.

32 Halstead SB, Porterfield JS, O’Rourke EJ: Enhancement of dengue virus infection in monocytes by flavivirus antisera. Am J Trop Med Hyg 1980;29:638-642.

-33 Srichaikul T, Nimmannitya S: Haematology in dengue and dengue haemorrhagic fever. Baillieres Best Pract Res Clin Haematol 2000;13:261-276.

-34 Mitrakul C, Poshyachinda M, Futrakul P, Sangkawibha N, Ahandrik S: Hemostatic and platelet kinetic studies in dengue hemorrhagic fever. Am J Trop Med Hyg 1977;26:975-984.

-35 Srichaikul T, Nimmannitya S, Sripaisarn T, Kamolsilpa M, Pulgate C: Platelet function during the acute phase of dengue hemorrhagic fever. Southeast Asian J Trop Med Public Health 1989;20:19-25.

-36 Mosquera JA, Hernandez JP, Valero N, Espina LM, Anez GJ: Ultrastructural studies on dengue virus type 2 infection of cultured human monocytes. Virol J 2005;2:26.

37 Fink K, Ng C, Nkenfou C, Vasudevan SG, van Rooijen N, Schul W: Depletion of macrophages in mice results in higher dengue virus titers and highlights the role of macrophages for virus control. Eur J Immunol 2009;39: 2809-2821.

-38 Wu SJ, Grouard-Vogel G, Sun W, Mascola JR, Brachtel E, Putvatana R, Louder MK, Filgueira L, Marovich MA, Wong HK, Blauvelt A, Murphy GS, Robb ML, Innes BL, Birx DL, Hayes CG, Frankel SS: Human skin Langerhans cells are targets of dengue virus infection. Nat Med 2000;6:816-820.

-39 Durbin AP, Vargas MJ, Wanionek K, Hammond SN, Gordon A, Rocha C, Balmaseda A, Harris E: Phenotyping of peripheral blood mononuclear cells during acute dengue illness demonstrates infection and increased activation of monocytes in severe cases compared to classic dengue fever. Virology 2008;376:429-435.

40 Wang S, He R, Patarapotikul J, Innis BL, Anderson R: Antibody-enhanced binding of dengue-2 virus to human platelets. Virology 1995;213:254-257.

41 Lin CF, Lei HY, Liu CC, Liu HS, Yeh TM, Wang ST, Yang TI, Sheu FC, Kuo CF, Lin YS: Generation of IgM antiplatelet autoantibody in dengue patients. J Med Virol 2001;63:143-149.

42 Yang KD, Lee CS, Shaio MF: A higher production of platelet activating factor in ex vivo heterologously secondary dengue-2 virus infections. Acta Microbiol Immunol Hung 1995;42:403-407.

43 Honda S, Saito M, Dimaano EM, Morales PA, Alonzo MT, Suarez LA, Koike N, Inoue S, Kumatori A, Matias RR, Natividad FF, Oishi K: Increased phagocytosis of platelets from patients with secondary dengue virus infection by human macrophages. Am J Trop Med Hyg 2009;80:841-845.

-44 Wan SW, Yang YW, Chu YT, Lin CF, Chang CP, Yeh TM, Anderson R, Lin YS: Anti-dengue virus nonstructural protein 1 antibodies contribute to platelet phagocytosis by macrophages. Thromb Haemost 2016;115:646656.

45 Huang YH, Liu CC, Wang ST, Lei HY, Liu HL, Lin YS, Wu HL, Yeh TM: Activation of coagulation and fibrinolysis during dengue virus infection. J Med Virol 2001;63:247-251.

-46 Puerta-Guardo H, Glasner DR, Harris E: Dengue virus NS1 disrupts the endothelial glycocalyx, leading to hyperpermeability. PLoS Pathog 2016;12:e1005738. 